\title{
ESTUDIO DE LA MONILIASIS MEDIANTE EL USO DE MARCADORES MOLECULARES
}

\author{
Maria Julia Silva Manco
}

\begin{abstract}
RESUMEN
Moniliophthora roreri es el agente causal de la Moniliasis en el cacao (Theobroma cacao), el cual produce efectos devastadores en los frutos. En nuestro país hay pocos estudios relacionados con los aspectos biológicos del patógeno y es inexistente aquellos estudios donde se utilicen herramientas biológicas como los marcadores moleculares. La utilización de estas herramientas servirá para conocer la diversidad genética que presenta este patógeno. El objetivo de este trabajo es el análisis de las nuevas técnicas para el estudio de la diversidad genética, que se convertirá en una alternativa para el desarrollo de programas de mejoramiento genético.
\end{abstract}

Palabras claves: Moniliophthora roreri, Marcadores moleculares, diversidad genética.

\section{SUMMARY}

Moniliophthora roreri is the causal agent of Moniliasis in cocoa (Theobroma cacao), which produces devastating effects on fruit. In our country there are few studies concerning the biology of the pathogen and is non-existent those studies where biological tools are used as molecular markers. The use of these tools serves to determine the genetic diversity presented by this pathogen. The aim of this paper is to implement new techniques for the study of genetic diversity. Becoming an alternative for the development of breeding programs.

Key words: Moniliophthora roreri, Molecular markers, genetic diversity.

\section{MONILIASIS}

\section{- Origen y distribución}

La Moniliasis se observo por primera vez en 1914, cerca a la ciudad de Quevedo, Ecuador, de este país $M$. roreri se disemino a Colombia y Perú y después a Venezuela y Panamá y más recientemente a Costa Rica, constituyéndose una amenaza considerable para la industria del cacao en América Central y otras regiones de América tropical. (Thurston, 1989).

La presencia de Moniliasis en el Perú, según reportes del año 1950 indicaban, que estaría presente en JaénCajamarca; Tingo Maria-Huánuco y en la ConvenciónCuzco. Pero en el año 1988, se detectó por primera en Bagua Grande, departamento de Amazonas. En 1991 se observó en Tingo María , en el año 1994 se detectó en Pasco y en 1995 se había diseminado al Valle de los Ríos Apurímac y Ene (VRAE), la zona con mayor área sembrada con cacao en el país, que comprende territorios de Junín, Ayacucho y Cusco. En 1998 se confirmó su presencia en el Valle del Río Urubamba, provincia de la Convención, Cusco. Este mismo año se lo identificó también en Junín. La enfermedad está diseminada prácticamente en todas las áreas cacaoteras significativas del país. (SENASA, 2003).

\section{- Importancia económica}

Los daños que causa esta enfermedad son muy variables de un país a otro, dependiendo principalmente de los factores ambientales (Hernández, 1996). En algunos países afectados por esta enfermedad, constituye uno de los factores limitantes por ocasionar perdidas total o casi total de las mazorcas enfermas. (Ferres, 1990).

En nuestro país el cultivo de cacao constituye una de las principales actividades productivas en la amazonia peruana, especialmente en zonas de selva alta, donde existen unas 42,000 ha sembradas con esta especie. La productividad de este cultivo ha sido baja, esto se puede explicar por la incidencia de plagas, siendo la más importante la Moniliasis, siendo el principal problema fitosanitario, disminuyendo los rendimientos drásticamente y obligando a muchos agricultores abandonar sus plantaciones. (SENASA, 2003). 
- Etiología

El microorganismo causal de la Moniliasis del cacao es el hongo Moniliophthora roreri (Cif. \& Par.) Evans, un hongo de la clase Deuteromicetes (Imperfecto) y del Orden Moniliales. Aun no se conoce su estado perfecto (sexual), por lo que se cree que su reproducción se realiza sólo asexualmente por conidios. (FHA, 2003)

\section{- Hospedero}

Moniliophthora roreri sólo ha sido encontrado atacando los frutos de los géneros Theobroma y Herrania. Los síntomas varían de acuerdo con la edad en que es infectado por el hongo.

\section{- Síntomas}

Los frutos son infectados principalmente en los primeros estados de crecimiento, la infección se desarrolla internamente, siendo esta más grave que el daño externo, pues se pierden casi todas las almendras, sin importar la edad de la mazorca. Este proceso de formación del hongo y los síntomas visibles se observan cuando el ciclo de vida del patógeno es avanzado (Cuadro 1). Uno de los síntomas más común de esta enfermedad es la aparición de la mancha color café, que puede extenderse hasta cubrir todo el fruto. (Rodríguez, 2005).

Cuadro 1: Desarrollo de síntomas producidos por Moniliophthora roreri en frutos de cacao

\begin{tabular}{c|c||c|c|c|c} 
Edad del fruto & \multicolumn{5}{|c}{ Síntomas y Signos } \\
\hline Días * & Deformación & Puntos & Manchas & Isla verde & Esporulación \\
\hline$<60$ & $\mathrm{X}$ & $\mathrm{X}$ & $\mathrm{X}$ & - & $\mathrm{X}$ \\
$60-110$ & - & $\mathrm{X}$ & $\mathrm{X}$ & - & $\mathrm{X}$ \\
$>110$ & - & $\mathrm{X}$ & - & $\mathrm{X}$ & - \\
\hline \hline
\end{tabular}

\section{- Controlde la enfermedad}

El control de la Moniliasis del cacao, puede ser por los siguientes medios: i) por medios químicos.- haciendo uso de fungicidas. ii) por medios culturales.- crear un ambiente favorable al cultivo y desfavorable a la vez al patógeno, para que la enfermedad tenga poco efecto en la cosecha. iii) por resistencia genética.- entre los cultivares de la especie de Theobroma cacao hay diferencias en la susceptibilidad a $M$. roreri, lo cual muestra que en esta especie existen fuentes de resistencia al hongo.

\section{MARCADORES MOLECULARES}

Los marcadores del acido desoxirribonucleico ADN se basan fundamentalmente en el análisis de las diferencias en pequeñas secuencias del ADN entre individuos. Las técnicas empleadas para ello son muy diversas y dan nombre a los distintos tipos de marcadores, los cuales pueden ser de carácter dominante o codominante.

Algunos ejemplos de ellos son: Polimorfismo de la longitud de los fragmentos de restricción (RFLP), Amplificación aleatoria del ADN polimórfico (RAPD), Polimorfismo en la longitud de los fragmentos amplificados (AFLP), Microsatélites o Secuencias simples repetidas (SSR) (Cuadro 2).

\section{- Polimorfismo de la longitud de los fragmentos derestricción (RFLP)}

Técnica basada en la hibridación de una secuencia clonada con fragmentos de secuencias homologas distribuidas a los largo del genoma, lo que la hace apropiada para una serie de estudios.

El polimorfismo observado, se debe a que el ADN de individuos genéticamente distintos, van a diferir en la secuencia de nucleótidos a lo largo de la cadena. El ADN en estudio, es digerido por una enzima de restricción, que corta el ADN en una secuencia determinada.

Los fragmentos clivados por la enzima de restricción se separan por su tamaño mediante electroforesis y se transfieren a una membrana donde son hibridados con la sonda, la cual solamente va hibridar fragmentos de ADN inmovilizados en la membrana que presenten la secuencia complementaria a la misma. Para visualizar los polimorfismos se expone la membrana a una placa radiográfica (Azofeifa, 2006).

- Amplificación aleatoria del ADN polimórfico (RAPD)

Esta técnica es una modificación que se realizó en la metodología PCR (reacción en cadena de la polimerasa) la cual consistió en sustituir, el uso de un determinado par de primers, por un primers aleatorio con la capacidad de unirse a muchos loci diferentes, el cual se usa para amplificar secuencias al azar de un patrón complejo de ADN.

El polimorfismo producido por la técnica RAPDs se denominan "marcadores RAPDs", puede resultar de cualquier cambio en la secuencia o sitio de unión del primer (mutación puntual), lo cual impide que el primer se una a la cadena, o también pueden ser producto de cambios que alteren el tamaño o impidan la exitosa amplificación delADN molde (Azofeifa, 2006). 
- Polimorfismo en la longitud de los fragmentos amplificados (AFLP)

Son considerados marcadores de alta eficacia, permiten el análisis de un elevado número de loci por experimentos sin requerir información previa sobre su secuencia, son en su mayoría dominantes y altamente reproducibles (Azofeifa, 2006).

El polimorfismo de los AFLPs depende de la relación entre el número de nucleótidos selectivos en los "primers" de la PCR y la complejidad del genoma (Ferreira, 1998).

- Microsatélites o Secuencias simples repetidas (SSR)

Son regiones genómicas hipervariables constituidas por repeticiones en "tandem" de unos pocos pares de bases ( 1 a 4) flanqueadas por secuencias de copias únicas. La base genética del polimorfismo detectado en microsatélites, se basa en la variabilidad del número de repeticiones en "tandem" y consecuentemente del tamaño del microsatélite amplificado en individuos de una especie. Por el alto polimorfismo que presentan por locus (multialelismo) se los considera los marcadores ideales para el mejoramiento en especies (Ferreira, 1998).

Cuadro 2: Resumen de las principales características de los marcadores

\begin{tabular}{c||c|c||c|c} 
Características & RFLP & RAPD & AFLP & SSR \\
\hline $\begin{array}{c}\text { Nivel de } \\
\text { polimorfismo } \\
\text { que detecta }\end{array}$ & Medio & Medio & Medio & Alto \\
Dominancia & Codominante & Dominante & $\begin{array}{c}\text { Codominante/ } \\
\text { Dominante }\end{array}$ & Codominante \\
$\begin{array}{c}\text { Número de loci } \\
\text { Abundancia en } \\
\text { el genoma }\end{array}$ & Multiloci & Multiloci & Multiloci & Multiloci \\
& Muy alta & Alta & Media
\end{tabular}

\section{MARCADORES MOLECULARES EN EL ESTUDIO DE Moniliophthora roreri}

Se sabe que Moniliophthora roreri, muestra uniformidad genética en América Central, Ecuador y Perú donde se ha dispersado en forma clonal encontrándose actualmente en una fase invasiva. (Grisales et al 2007).

La fuente de esta variación reside en las mutaciones y la reproducción sexual entre aislamientos en el hospedante silvestre Theobroma gileri que genera un nuevo arreglo de genes, suficiente para responder a la presión de selección, lo que explicaría por qué $M$. roreri ha desplazado rápidamente a $M$. perniciosa en el Perú a pesar de que su presencia en este país es muy reciente. (Grisales et al 2007, Phillips et al 2007).

Estudios con AFLP y perfiles de ISSR en cepas de $M$. roreri provenientes de América Central y Sudamérica, fueron analizados, proporcionando pruebas limitadas para apoyar la hipótesis de que M. roreri es capaz de la reproducción sexual. Los niveles más altos de la diversidad genética ocurren en Colombia y no en el Ecuador como se creía originalmente. De datos de secuencia de la región del espaciador interno transcrito de la repetición del ADNr nuclear son congruentes con los resultados de AFLP y ISSR, donde se designaron cinco grupos genéticos para Moniliophthora roreri en América Latina, dos endémicos de Colombia: Grupo Co-oriente restringido al oriente, y Grupo Co-central restringido a la región central, el Grupo Gileri endémico de Ecuador localizado al noroccidente, los dos restantes se encuentran en fase invasiva, el Grupo Bolívar localizado en el oriente de Colombia (Norte de Santander), periferia de Ecuador, Venezuela y Perú, y el Grupo Co-occidente en el occidente de Colombia, centro de Ecuador, Panamá, Costa Rica, Nicaragua y Honduras (Phillips et al 2007).

Este tipo de estudios son fundamentales para el diseño de estrategias encaminadas al control de Moniliasis, y programas de mejoramiento genético de Theobroma caco $L$. con la selección de genotipos resistentes a las variantes de $M$. roreri, pues la difusión de $M$. roreri en nuevas áreas y países mediados por la actividad humana puede incrementarse. Estos estudios permitirá mejorar las condiciones fitosanitarias de los cultivos de cacao.

\section{LITERATURA CITADA}

AZOFEIFAA., 2006. Uso de Marcadores Moleculares en Plantas; Aplicaciones en frutales del Trópico. Agronomía mesoamericana Vol. 17 (2). pp. 221242.

FERRES VJ. 1990. Caracterización de clones de cacao (Theobroma cacao L.) resistentes y susceptibles a la Moniliasis (Moniliophthora roreri [Cif. \& Par.] Evans et al.) Mediante marcadores RFLP. [Tesis Maestria]. Centro agronómico tropical de investigación y enseñanza. Costa Rica. 101p.

FERREIRA ME, GRATTAPAGILA D. 1998. Introducción al Uso de Marcadores en el Análisis Genético. $1^{\text {ra }}$ Edición. Brasilia: EMBRAPACENARGEN; p. 220.

FHA, APROCACAHO, PROMOSTA. 2003. Identificación y Control de la Moniliasis del Cacao. pp.: 1-18. 
GRISALES SP, AFANADOR L. 2007. Análisis de Variabilidad Genética en Moniliophthora roreri con AP-PCR y RAPD en Antioquia - Colombia. Rev. Colombiana de Biotecnología Vol.9 (2). pp. 15-32.

HERNÁNDEZ TA. RIOS R. ARÉVALO E. ARANZAZU F. 1996. Monilia del Cacao; Detección, distribución y control en el Perú. Programa de las Naciones Unidas para la Fiscalización Internacional de Drogas. Tingo Maria, Perú. OSP/UNDCP. 31p. (Informe Técnico Proyecto AD/PER/759-UNDCP-OSP)

PhILLIPS MW, AIME MC AND WILKINSON MJ. 2007. Biodiversity and biography of the cacao
(Theobroma cacao) pathogen Moniliophthora roreri in tropical America. Plant Pathology 56. pp. 911-922.

RODRÍGUEZ E, MUJICA J, CUBILLOS G, 2005, Manejo Integrado de la Moniliasis en el Cultivo del Cacao. Boletín técnico. pp.:1-24.

Servicio Nacional de Sanidad Agraria (SENASA). 2003. http:www.senasa.org.pe

THURSTON H, GALINDO J, 1989. Enfermedades de cultivos en el Trópico. Centro Agronómico Tropical de Investigación y enseñanza (CATIE); (225): pp 144-151. 